\title{
Control of incompatibilities in the production of helmets for mining
}

\author{
Piotr Sygut ${ }^{1, *}$ \\ ${ }^{1}$ Department of Production Engineering and Safety, Faculty of Management, Czestochowa University \\ of Technology, ul. Armii Krajowej 19B, 42-200 Czestochowa, Poland
}

\begin{abstract}
The paper presents the results of tests carried out in one of the national enterprises producing personal protection equipment. Characteristics of individual protection measures are presented, including those found in the construction and equipment of a protective helmet for the mining industry. In addition, proposals for improving the production process were presented in order to eliminate or limit the number of incompatibilities occurring in a given process.
\end{abstract}

\section{Introduction}

There are many workplaces in production companies, where work can have unpleasant consequences in relation to the health and even life of the employee [1]. Therefore, in order to reduce or completely eliminate the risk of a hazard, all possible technical and organizational activities should be carried out. In the event of failure of that action and not receiving the expected results, individual protection measures that are the sole and final protection of the employee must be taken. It follows from the general health and safety regulations that the elements of individual protection should be used as a last resort and treated as the last link of protection.

An item of personal protection means an equipment or device that is intended to be worn or used by an explorer. They are used to protect against one or more elements that threaten the safety and life of the user. A protective agent can be [2,3]:

- a set of a certain number of devices or types of protective accessories, e.g. a respiratory protection device connected to a protective helmet,

- a protective device that is connected with non-protective equipment, e.g. a protective helmet equipped with a mining lamp,

- replaceable components or parts of individual protection elements, eg filters for halfmasks,

- systems that are used together with personal protective equipment to connect them to external devices. These devices are not intended to be held or worn, e.g. air filters, which are used for the hose apparatus as respiratory protection.

The employer is responsible for the used personal protective equipment. It should provide employees, free of charge, carefully selected for hazards, protective elements and provide a method for their storage, maintenance, cleaning, disinfection and possible repairs.

\footnotetext{
*Corresponding author: piotr.sygut@wz.pcz.pl
} 
In addition, he should organize training in health and safety and the use of personal protective equipment [3].

To ensure proper functions, personal protective equipment should meet a number of specific requirements, including those that relate to aspects related to their design and manufacture. Confirmation that the product meets these requirements is the regulation of the Minister of Economy. On specific requirements for personal protective equipment. The basic requirements, the procedure and conditions for the assessment of conformity, as well as the design and method of CE marking are elaborated in this regulation [3].

Moreover, the product should guarantee proper protection of the user:

- be properly selected for the threat;

- not increase the risk;

- be selected in accordance with the prevailing conditions at a given workplace;

- be ideally suited to the user after the required adjustment.

In the countries belonging to the European Union, the criteria, scope, and compliance with the provisions of SOI are set out in Directive 89/686 / EEC, which introduced the divisions of these elements. It refers to the risks that occur in a given workstation, dividing the risk into three categories [4]:

Category I - includes measures that protect against diseases or injuries with a low degree of harmfulness, do not cause long-term discomfort and absence of an employee at work. A declaration of conformity of the European Union is required.

Category III is a means that protects against such threats as death or injuries that can cause severe and unversible injuries. It includes respiratory protection equipment, fall protection equipment and protection against electric shock.

Category II covers those personal protective equipment that do not belong to category I or III, they are: hearing protection, goggles, industrial helmets, safety goggles, protective clothing against possible mechanical hazards, shoes, gloves [4-6].

Before starting to choose protective measures, first identify the hazards that occur in the work environment and assess the occupational risk. If necessary, the emission of these harmful or dangerous factors is measured, and the results obtained are compared with the admissible values. If we take into account the manner in which harmful and dangerous factors affect the human body, the following sets of personal protective equipment are distinguished:

- protective clothing,

- measures to protect the upper limbs,

- measures to protect the lower limbs,

- face and eye protection,

- hearing protection,

- head protection measures,

- respiratory protection elements,

- protection against falling from a height.

There are many positions in various branches of industry, i.e. forestry, mining, construction, energy, which are at risk of head injuries. The most serious of them are mechanical injuries, which may be the result of an impact on dangerous stationary elements or by falling elements occurring at a given workplace. Activities performed in various positions have different specifications and it is not always possible to eliminate the threats arising from them. In such circumstances, the employer is obliged to provide the employee with an appropriate protective helmet, appropriate to the type of hazards [7].

Helmets, in addition, can protect the head against electric shock: electric shock, liquid metal splashes, transverse compressive forces, high temperatures. They can also be used as a base for the installation of eye shields, hearing protectors, respirators, neck guards, and ancillary equipment [7]. 


\section{Characteristics of the analyzed subject of research}

The study carried out research on the production of a protective helmet for the mining industry. It is a product of a Polish company producing the highest class protective equipment for civilians, as well as equipment and protective equipment for the army, police and etc.

The helmet has a constructionally reinforced shell, adjustable truss and many other necessary elements that allow its universal use, eg: chinstrap, visor protecting the face, potnik, rain gutter, ventilation holes, fixtures for fixing the lamp, cord and hearing protectors. The shell of the helmet is made of ABS. The manufacturer guarantees the operational parameters of the helmet within 5 years.

Materials used for the production of the helmet guarantee its electroinsulation up to 440 $\mathrm{V}$ and the ability to use at temperatures from -20 to $+50^{\circ} \mathrm{C}$. Due to its antielectrostatic properties, the helmet is approved for use in potentially explosive areas: $0,1,2,20,21,22$. In particular, it can be safely used in the presence of combustible media with a minimum ignition energy $>0.1 \mathrm{~mJ}$, including - methane and coal dust, especially - in climatic conditions prevailing in underground mining plants (excavations classified as methane explosion hazard)", "b" and "c" and for the coal explosion hazard classes "A" and "B"). It is predicted for use mainly in mining, metallurgy, power engineering, construction and in those services where there is a risk of explosion. The helmet meets the requirements of the Polish standard PN-EN 397:1997/A1:2002 together with additional requirements, i.e. resistance to very low temperature $\left(-20^{\circ} \mathrm{C}\right)$ and electrical insulation. The helmet is characterized by a small weight - below $350 \mathrm{~g}$ with full additional equipment for mining.

\section{Analysis of the incompatibility of the subject of research}

In the analyzed production company, research was carried out on the observation of the production process of the protective helmet. Nine discrepancies were detected during the weekly observations. The discrepancies are presented in Table 1 together with the frequency of occurrence and their percentage section. Based on this data, the ParetoLorenzo chart was made (Fig. 1) [8, 13].

Analyzing the received data in Table 1 and Fig. 1, it can be seen that the first two discrepancies (scratches, inaccurate shell casting and cracks and deformations on the eyeface shield) account for over $60 \%$ of all non-conformities observed in this process. Incompatibility scratches, inaccurate casting of the shell does not endanger the safety of the helmet operation by users, while for the new product it is undesirable due to the understatement of the aesthetic value of the product. In the case of the second in number of occurrences of non-compliance - the scratches and deformations on the eye-face cover are also the understatement of the aesthetic value of the product, but also some scratches and distortions caused visual field distortions and distorted vision for the user of the helmet.

For these discrepancies, guidelines for improving the production process have been developed. Fig. 2 presents the Ishikawa diagram [9-12] for the problem of cracks, inaccurate casting of the shell. This diagram was implemented on the basis of brainstorming carried out among the employees of the analyzed plant, which take an active part in the preparation and implementation of the helmet's production. 
Table 1. Detected incompatibility during the period consideredBląd! Nieprawidłowe lącze.

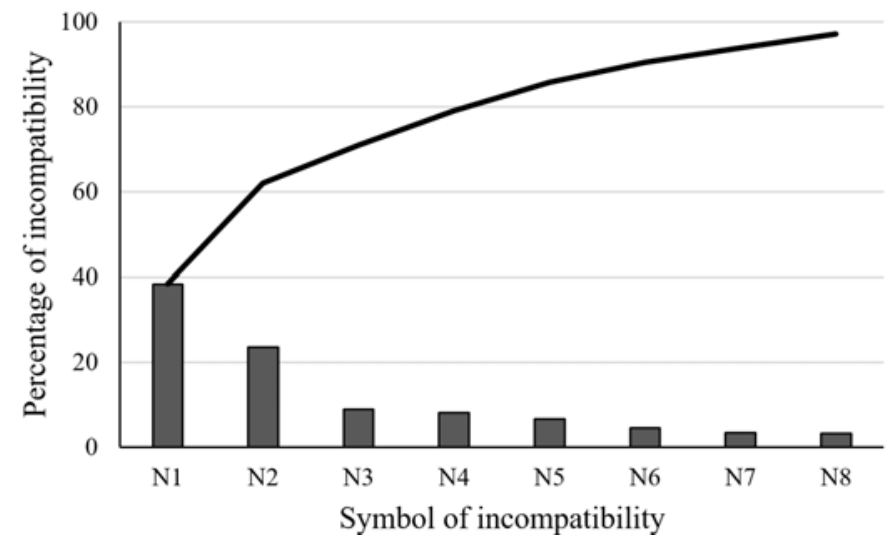

Fig. 1. Pareto-Lorenz chart for incompatibility in the production process of a protective helmet for the mining industry 


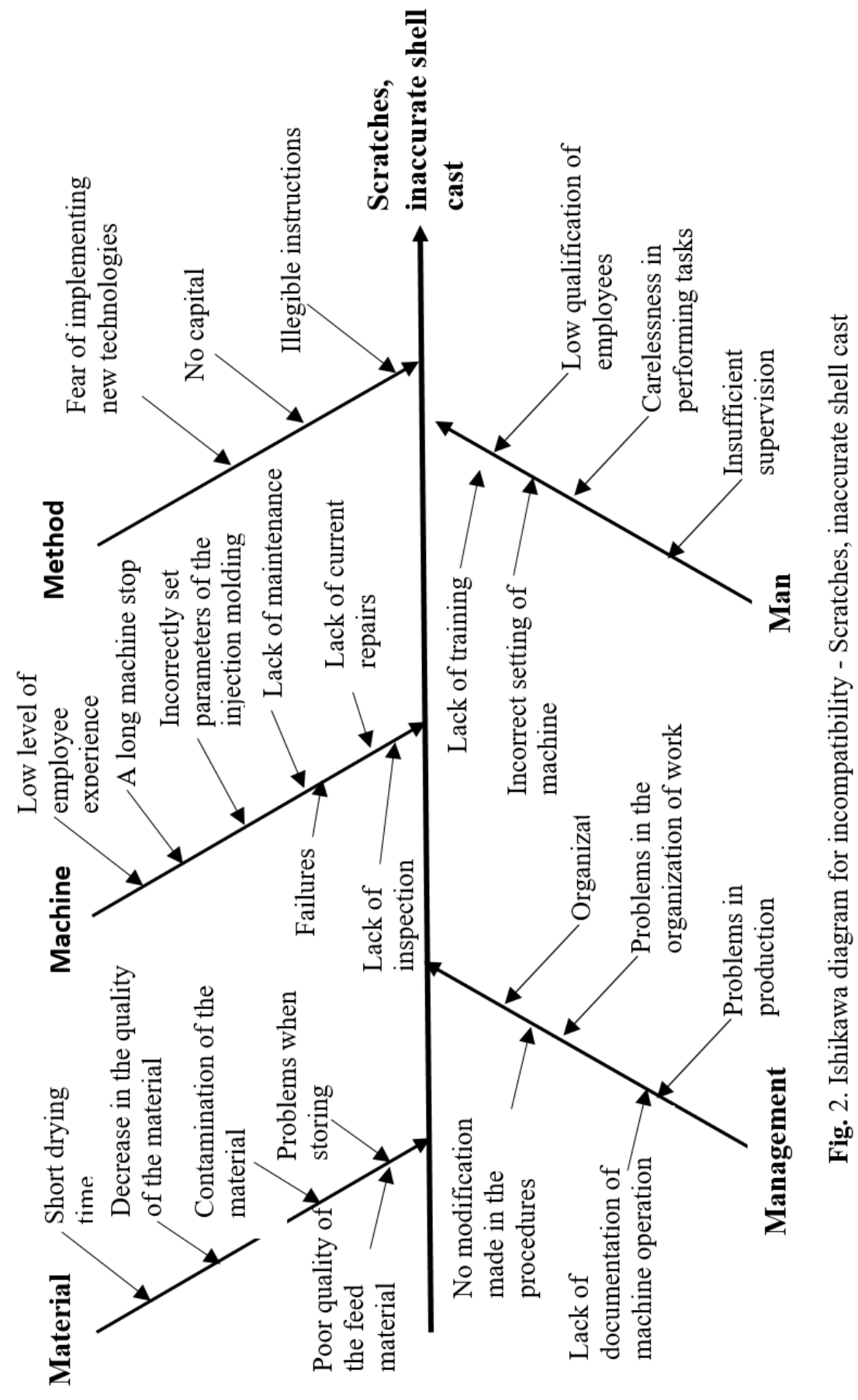

Analyzing the data shown in Fig. 2, it can be concluded that the non-compliance data is in most cases the resultant of human error (machine operator / warehouseman). This is due to the fact that the lack of sufficient human attention to the implemented process and 
procedures causes a malfunction of the machine. For example, lack of attention when retooling and maintaining the injection molding machine causes errors in the correct setting of the production process. Failure to observe the mold heating time causes incorrect casting or missing material in the cast product. The lack of control on the part of the management causes relaxation among production workers. The material itself had a low degree of disagreement. There were sporadic problems with improper material holding and drying. There were occasional problems with improper material holding and drying.

\section{Conclusion}

In order to minimize or completely eliminate a given nonconformity, corrective actions should be implemented in the entire enterprise with the associated control (process control, employee self-control, employee control). This requires greater involvement of the company's management division and people supervising the production line. It is necessary to carry out training for employees, introduce workplace training, introduce more clear instructions at the station, introduce employees' motivation. The works must be carried out at every level in the hierarchy of the analyzed enterprise. Because the company has a large production potential, the effects of the proposed improvement actions should be visible immediately after their introduction (impact on the improvement of production quality and its efficiency).

\section{References}

1. A. A. Godwin, T. R. Eger, WJoPA\&H, 47, 23 (2014)

2. C.J. Behr, A. Kumar, and G.P. Hancke, Proceedings of the IEEE International Conference on Industrial Technology (2016)

3. A. Pościk, Dobór środków ochrony indywidulanej,(CIOP, Warszawa, 2000)

4. E. Balańska, M. Flotyn, Środki ochrony indywidualnej. Informacje dla pracodawcy, (Urz. UIE, Warszawa, 2001)

5. Baszczyński, K. 2018, IJoOSE, 24, 171 (2018)

6. M.A. Mououdi, J. Akbari and M. Mohammadi Khoshoei, EiD (2018)

7. K. Baszczyński, Ochrona przed upadkiem z wysokości, (CIOP, Warszawa, 2001)

8. P. Sygut, Production Engineering Archives 6 (1), 14-16 (2015)

9. B. Chokkalingam, V. Raja, J. Anburaj, R. Immanual, and M. Dhineshkumar, AoFE 17, 174 (2017)

10. P. Milosavljevic, D. Pavlovic, M. Rajic, A. Pavlovic and C. Fragassa, IJoCEEaLL, 28, 24 (2018)

11. J. Pietraszek, A. Gądek-Moszczak, T. Torunski, Adv. Mat. Res.-Switz. 874, 139 (2014)

12. M. Zenkiewicz, T. Zuk, J. Pietraszek, P. Rytlewski, K. Moraczewski, M. Stepczynska, Polimery, 61, 835 (2016)

13. R. Ulewicz, J. Selejdak, S. Borkowski, M. Jagusiak-Kocik, Metal 2013: $22^{\text {nd }}$ International Conference on Metallurgy and Materials, 1926-193 (2013). 